\title{
A Case of Hyperplastic Gastric Polyp Presenting with Massive Gastrointestinal Bleeding
}

\author{
Sung Joon Kim, Chan Seo Park', Sung Bum Kim', Si Hyung Lee ${ }^{1}$ \\ Department of Internal Medicine, Yeungnam University Yeongcheon Hospital, Department of Internal Medicine, Yeungnam University College \\ of Medicine ${ }^{1}$, Daegu, Korea
}

\begin{abstract}
Hyperplastic polyps are the most common histological findings among benign gastric polyps. The characteristics of gastric hyperplastic polyps are usually subclinical, small, sessile form, and solitary lesions occurring in the antrum. With increasing size, they can present with dyspepsia, nausea, melena or iron deficiency anemia due to chronic blood loss. Especially polyps with size exceeding $2 \mathrm{~cm}$ is defined as a giant gastric polyp and comprises $2 \%$ of gastric hyperplastic polyps. However, massive upper gastrointestinal bleeding caused by gastric hyperplastic polyps is rare. Here, we report a case of a 64-year-old male patient with massive bleeding caused by a giant gastric polyp which needed urgent endoscopic hemostasis and was confirmed as a hyperplastic polyp. According to our experience, physicians should be aware that gastric hyperplastic polyp might result in massive upper gastrointestinal bleeding. (Korean J Helicobacter Up Gastrointest Res 2013;13:252-257)
\end{abstract}

Key Words: Stomach; Polyp; Hemorrhage

\section{INTRODUCTION}

Polyp is defined as an abnormal growth originating from mucosal layer among lesions that causes mucosa protrusion into gastrointestinal lumen. ${ }^{1}$ Polyp can occur at any place of stomach and is classified histologically as hyperplastic polyp, fundic gland polyp, adenomatous polyp and inflammatory polyp. ${ }^{2}$ The accurate prevalence is not known but reported to be $0.4 \%$ at autopsy, $2 \%$ in symptomatic patients undergone upper endoscopy, and $5 \%$ in asymptomatic undergone upper endoscopy. ${ }^{3}$

Polypoid lesion refers to lesion that shows shape of polyp on endoscopic examination. On autopsy, incidence of polypoid lesion has been reported to be $0.12 \sim 0.8 \%$ and on endoscopic examination, as high as $8.7 \%{ }^{4}$

Hyperplastic polyp is the most common benign epithelial polyp that arises in stomach and comprises $80 \%$ to 90\% of all gastric polyps. ${ }^{5,6}$ Presenting symptoms in patients with gastric polyp includes epigastric pain, abdominal discomfort, nausea, and vomiting, but most diag-

Received: June 16, 2013 Accepted: August 6, 2013

Corresponding author: Si Hyung Lee

Department of Internal Medicine, Yeungnam University College of Medicine, 170, Hyeonchung-ro, Nam-gu, Daegu 705-717, Korea

Tel: +82-53-620-3830, Fax: +82-53-654-8386, E-mail: dr9696@nate.com noses are made incidentally during radiologic examination or upper endoscopy in patients without symptoms and thus clinical significance of symptoms associated with polyp is small.

They come in forms of solitary or multiple polyp, and 90\% of hyperplastic polyps are reported to accompany Helicobacter pylori infection. ${ }^{6}$ Giant hyperplastic polyp is defined as polyp size that is larger than $2 \mathrm{~cm}$, and as size increases, possibility of malignant transformation increases and clinically significant symptoms and signs, including iron deficiency anemia due to chronic blood loss, upper gastrointestinal bleeding, and gastric outlet obstruction, can also occur. ${ }^{7,8}$

Upper gastrointestinal bleeding due to gastric hyperplastic polyp is uncommon and it is hard to cause massive bleeding like in our patient. We report a case of giant gastric hyperplastic polyp causing hematemesis for 4 times with literature review.

\section{CASE REPORT}

A 64-year-old man visited emergency room for hematemesis with amount of $200 \mathrm{~mL}$ for 4 times. His past medical history included hypertension with medication for 10 years and stable angina treated with aspirin 100

Copyright $\odot 2013$ Korean College of Helicobacter and Upper Gastrointestinal Research

(.) The Korean Journal of Helicobacter and Upper Gastrointestinal Research is an Open-Access Journal. All articles are distributed under the terms of the Creative Commons Attribution Non-Commercial License (http://creativecommons.org/licenses/by-nc/3.0) which permits unrestricted non-commercial use, distribution, and reproduction in any medium, provided the original work is properly cited. 

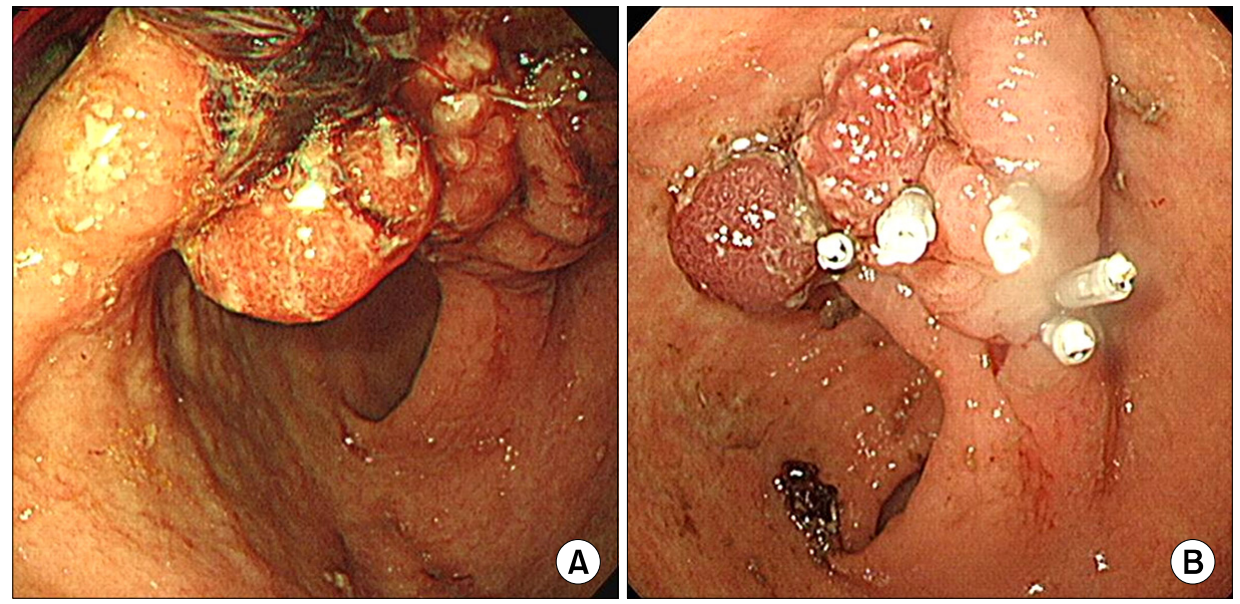

Fig. 1. Endoscopic view. (A) An about $5.0 \mathrm{~cm}$ sized lobulated and pedunculated polyp with adherent clot in distal antrum of stomach was observed. (B) Endoscopic hemoclipping was done in bleeding focus.

$\mathrm{mg}$ /day and clopidogrel $70 \mathrm{mg} /$ day in our cardiologic department until the day before he visited emergency department. He examined upper gastrointestinal series 3 months prior for health screening and no abnormality was found. He had no history of alcohol intake or smoking. Moreover, no characteristic familial history was found. His vital signs at visit of emergency department were blood pressure 100/80 $\mathrm{mmHg}$, pulse rate 100 beats/min, respiration rate 20 times/min and body temperature $36.5^{\circ} \mathrm{C}$. At physical examination, mental state was alert. Skin was warm and dry, conjunctiva was pale, and sclera was anicteric. There were no lymph node enlargement in head and neck and inguinal region. Respiration was normal in auscultation and heart sound was normal without murmur. Abdomen was flat and soft on palpation and bowel sound was normal without tenderness. Sign of hepatomegaly or splenomegaly was not found. Peripheral blood test done at the time of visit showed following. Hemoglobin $10 \mathrm{mg} / \mathrm{dL}$, white blood cell count $9,740 / \mathrm{mm}^{3}$, platelet $202,000 / \mathrm{mm}^{3}$ and last hemoglobin level checked before visiting emergency room at cardiologic department was $14.5 \mathrm{mg} / \mathrm{dL}$. Other laboratory test showed no abnormality.

Upper gastrointestinal endoscopy done at emergency department revealed about $5 \mathrm{~cm}$ sized polypoid lesion at gastric antrum (Fig. 1A). When tracked with endoscopic forceps, stalk, branched in two ways, was seen at proximal $1 / 3$ portion and another branched stalk was seen at proximal 1/2 portion, forming characteristic Y-on-Y morphology. Bleeding was controlled by endoscopic hemo-

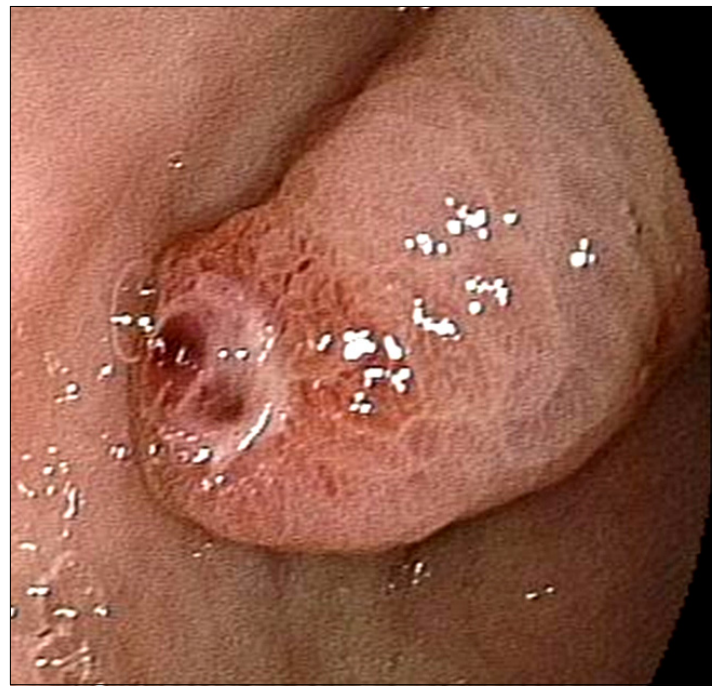

Fig. 2. Endoscopic view. A $2.5 \mathrm{~cm}$ sized polyp with exposed vessels was remained due to self-amputation by endoscopic hemoclipping.

clipping for 5 times and patient was hospitalized (Fig. 1B). Abdominal CT showed no abnormality.

Peripheral blood test done after the day of admission showed drop in hemoglobin to $6.9 \mathrm{mg} / \mathrm{dL}$ indicating possibility of massive re-bleeding and patients examined upper endoscopy again. Upper endoscopy revealed removed status of distal half of giant polyp due to tissue necrosis by hemoclip and only proximal site of the polyp was remained (Fig. 2). Active bleeding was not seen, but we executed exposed vessel by hemoclipping. Biopsy was done due to possibility of malignant transformation.

Pathologic report showed severe atrophy and chronic gastritis accompanying intestinal metaplasia. At 4th day of 

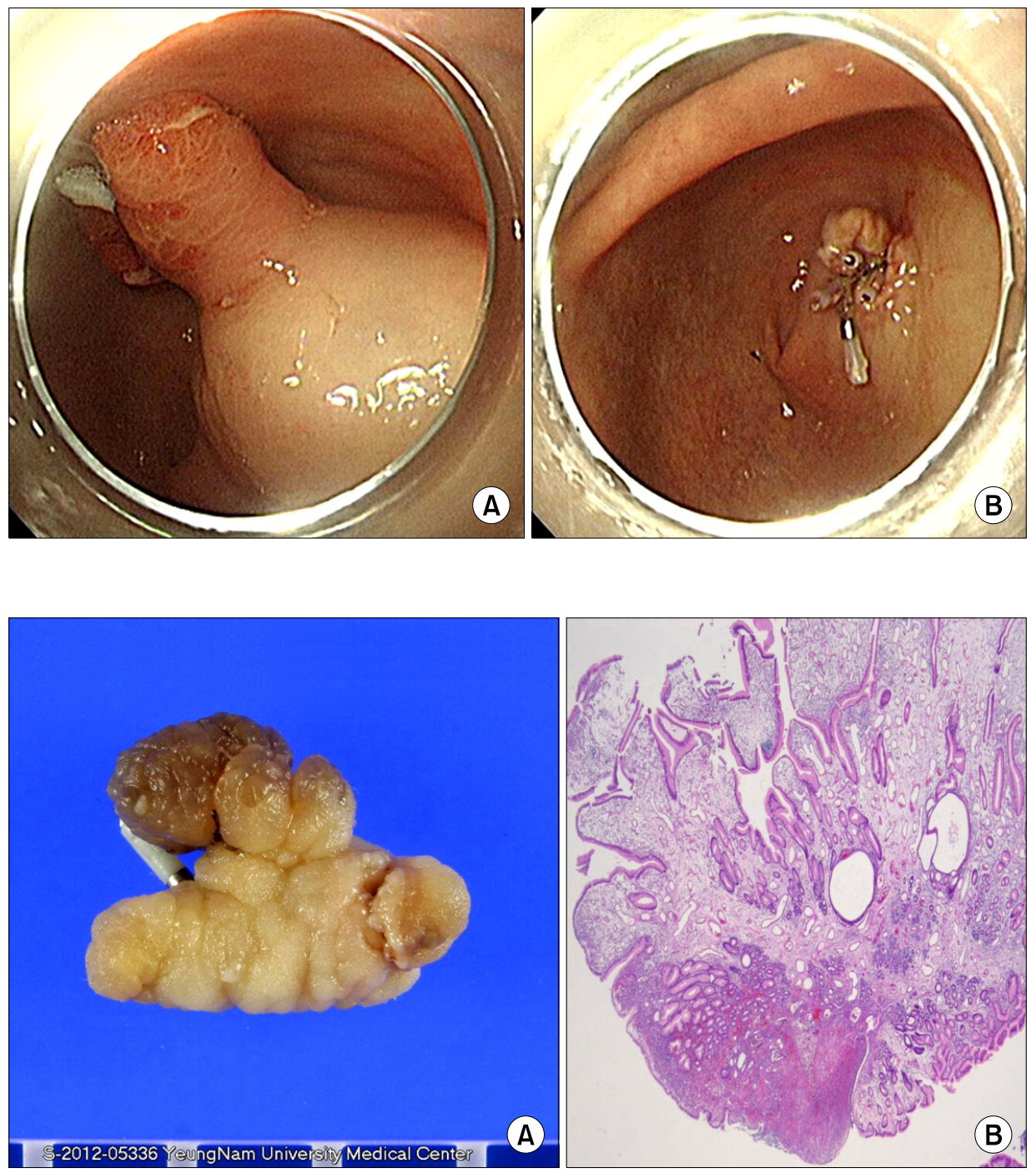

Fig. 3. Endoscopic view. (A) Hypertonic saline was injected and mucosal lifting was observed. (B) Remnant gastric polyp removed by endoscopic mucosal resection.
Fig. 4. Pathological view. (A) A $2.0 \times 2.5$ $\mathrm{cm}$ sized gross specimen was seen by photography. (B) Pathologic microscopic photo showed the gastric polyp which is elongated, tortuous or dilated foveola with ulceration and involvement of resection margin $(\mathrm{H} \& \mathrm{E}$, $\times 100)$. admission, the remnant polyp removed by endoscopic mucosal resection after taking patient's consent (Fig. 3A and B). Size of resected polyp was $2.5 \mathrm{~cm}$ (Fig. 4A) and final pathologic diagnosis was hyperplastic polyp which is different from the first pathologic report (Fig. 4B). Resection margin was positive.

Patient was discharged without further complications at 7 th day of admission. No local recurrence of hyperplastic polyp was found at 3 months, 6 months and 12 months follow up upper endoscopy (Fig. 5). In our case, Helicobacter pylori infection was not found.

\section{DISCUSSION}

Sessile hyperplastic gastric polyp is relatively the most common shape, but pedunculated form can be seen in large sized polyps. Especially size exceeding $2 \mathrm{~cm}$ is defined as giant gastric polyp and comprises $2 \%$ of hyperplastic polyp. Giant gastric hyperplastic polyps constitute of around $76 \%$ of all gastric polyps found.

Exact pathogenesis is not known yet, but it is known to be related to excessive regeneration reaction of gastric mucosal epithelium due to damage caused by chronic inflammation. ' Chronic gastritis, autoimmune gastritis, Helicobacter pylori infection, and bile regurgitation over remnant stomach after stomach resection are the causes 


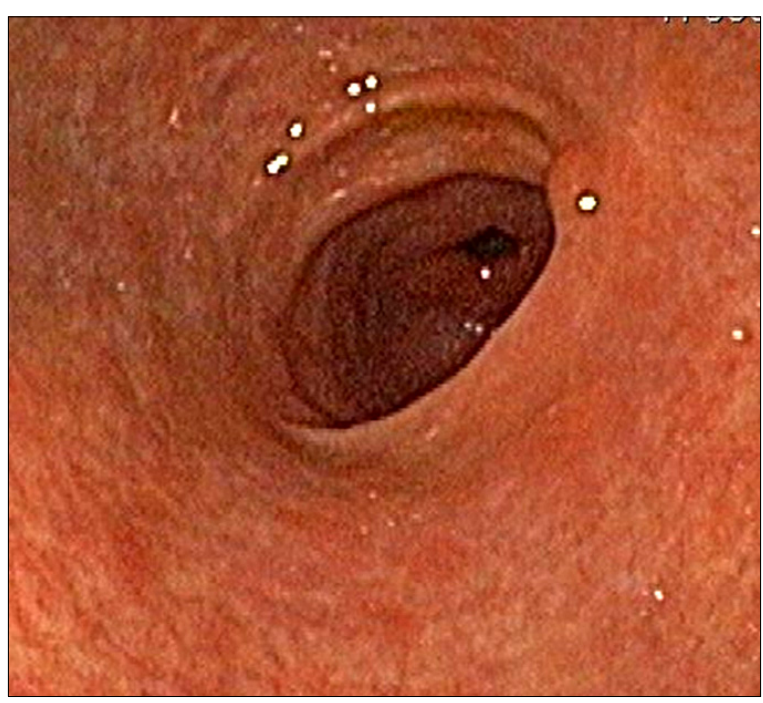

Fig. 5. Endoscopic view after 12 months. Only small post-endoscopic mucosal resection scar was noted.

of chronic inflammation. Cytomegalovirus gastritis, lymphocytic gastritis, amyloidosis, Zollinger-Ellison syndrome and gastric antral vascular ectasia are uncommonly related.

Association with Helicobacter pylori for pathogenesis is well known. ${ }^{10,11}$ Helicobacter pylori influence stromal and mesenchymal cell thereafter, activates expression of interleukin 1-beta or hepatocyte growth factor, and causes chronic inflammatory state. ${ }^{11-13} 90 \%$ of hyperplastic polyps are found to accompany Helicobacter pylori infection, and eradication of Helicobacter pylori infection leads to extinction of hyperplastic polyp, but re-infection with Helicobacter pylori causes hyperplastic polyp to recur. ${ }^{13}$ Other mechanism like hypergastrinemia is also related.

Although the pathophysiology of this giant hyperplastic polyps is uncertain, some lesions may develop from a focal cluster of small hyperplastic polyps that coalesced as they enlarged, resulting in the development of a conglomerate mass. Cheon et al. ${ }^{14}$ which studied characteristics of small gastrointestinal polyphoid lesion reported that size of polypoid lesion was most commonly $3 \sim 4$ $\mathrm{mm}$ and followed by above $5 \mathrm{~mm}$. Lesion with size above $6 \mathrm{~mm}$ was relatively less prevalent and $97.6 \%$ of all lesion was below $5 \mathrm{~mm}$ in size. Yamada type I and II was the most common form and a few had type III form and none had type IV form. Previous studies about form of polypoid lesion reported that Yamada type II and III was more prevalent. ${ }^{15}$ Our case was huge polypoid lesion with size of $5 \mathrm{~cm}$. The morphology of the lesion was Y-on-Y shaped pedunculated form (Yamada type IV).

Al-Haddad et al. ${ }^{16}$ reported that fourteen patients (1.4\%) revealed as a hyperplastic polyps in the gastric antrum among 987 patients who suspected gastrointestinal bleeding, multiple antral polyps were present in seven cases, the largest polyp measured $5 \mathrm{~cm}$, nine had documented iron deficiency, five of the patients reported melena, but there were none of them showed hematemesis. In other study during a 10-year period by Cherukuri et al., ${ }^{17} 7$ cases of giant gastric hyperplastic polyps were noted. The mean diameter of the giant hyperplastic polyps in the seven patients was $4.7 \mathrm{~cm}$ (range from $3 \mathrm{~cm}$ to $10 \mathrm{~cm}$ ) and symptoms of upper gastrointestinal bleeding presented in four patients. ${ }^{17}$

About 3.4\% of gastric polyp accompanies hematemesis, but a case accompanying massive bleeding causing more than half drop in normal hemoglobin level and re-bleeding after endoscopic treatment is very rare. Possibly, use of anti-platelet agents may aggravate massive bleeding in our patient. Unlike in most cases, Helicobacter pylori infection was not found in our case. Half of distal portion of polyp was amputated possibly due to mechanical vascular compression and tissues necrosis caused by hemoclip. Because we could not found out the amputated tissue, we can't exclude completely the possibility of malignant transformation of polyp. Thus, more meticulous follow-up strategy is essential.

By Cherukuri et al., ${ }^{17}$ Six (86\%) of the seven giant hyperplastic polyps appeared on double-contrast upper gastrointestinal examinations as multilobulated masses with trapping of barium in the interstices between lobules, producing distinctive radiographic findings. However, in our cases, giant gastric polyp was not found in radiologic studies of upper gastrointestinal series at 3 month prior for health screening and in abdominal CT done at admission. So patients having light symptoms, like abdominal discomfort, dyspepsia, nausea, vomiting without serious complications needs offensive endoscopic examination. Especially, giant hyperplastic polyps cannot be differentiated with certainty from polypoid carcinomas or other malignant lesions in the stomach by radiologic 
examination. Moreover, as size of hyperplastic polyp increases, it becomes pedunculated and these make it hard to differentiate hyperplastic polyp from adenomatous polyp or adenocarcinoma in radiologic examinations such as upper gastrointestinal series or abdominal $\mathrm{CT}^{17}$

The rate of malignant transformation of gastric adenoma is reported to be $6 \sim 75 \%$ and so, polypectomy is recommended. There is still debate on whether hyperplastic polyp undergoes malignant transformation, but 1.5 $\sim 2.1 \%$ is reported of malignant transformation in hyperplastic polyp. ${ }^{18}$ In study by Dang et al., ${ }^{19}$ hyperplastic gastric polyps are mostly benign but, they do have potential for malignant transformation and hence must be excised endoscopically or surgically, whichever may be feasible. Hyperplastic polyp of cardia, unlike other part of stomach, rarely undergoes malignant transformation.

As size of polyp increases, possibility to show symptoms and signs, like abdominal discomfort, dyspepsia, nausea, vomiting, and iron deficiency anemia due to chronic bleeding, increases. Therefore, endoscopy and biopsy are required for a definitive diagnosis. Giant hyperplastic polyp located at antrum can cause rare signs of hematochezia due to upper gastrointestinal bleeding or gastric outlet obstruction, ${ }^{7,8}$ so treatments including endoscopy or surgical removal and iron supplement is needed and careful follow up endoscopy is needed keeping in mind the possibility of malignant transformation or recurrence. $^{20}$

In our case, $5 \mathrm{~cm}$ sized giant gastric polyp accompanied acute massive bleeding and the bleeding was controlled by endoscopic hemoclipping, but showed progress of self removal in 12 hours and re-bleeding. Remnant polyp was removed by endoscopic mucosal resection and finally confirmed as hyperplastic polyp. However, pathological result can't be acquired in distal half of polypoid lesion due to spontaneous passage of self-amputated specimen and possibility of cancer cannot be completely ruled out. Resection margin of removed by endoscopic mucosal resection was positive. Fortunately, no signs of local recurrence were seen during three consecutive follow up upper endoscopy and showed favorable progress. We should keep in mind that hyperplastic gastric polyp can cause serious upper gastroin- testinal bleeding like in our case. Moreover, because of the possibility of transformation to malignancy, we suggest that asymptomatic patients with giant gastric hyperplastic polyp should be removed in advance.

\section{REFERENCES}

1. Kronborg O. Colon polyps and cancer. Endoscopy 2000; 32:124-130.

2. Carmack SW, Genta RM, Schuler CM, Saboorian MH. The current spectrum of gastric polyps: a 1-year national study of over 120,000 patients. Am J Gastroenterol 2009;104:1524-1532.

3. Ming SC, Goldman H. Pathology of the gastrointestinal tract. 1st ed. Philadelphia: WB Saunders, 1992.

4. Yoon WJ, Lee DH, Jung YJ, et al. Histologic characteristics of gastric polyps in Korea: emphasis on discrepancy between endoscopic forceps biopsy and endoscopic mucosal resection specimen. World J Gastroenterol 2006;12:4029-4032.

5. Zea-Iriarte WL, Sekine I, Itsuno M, et al. Carcinoma in gastric hyperplastic polyps. A phenotypic study. Dig Dis Sci 1996; 41:377-386.

6. Debongnie JC. Gastric polyps. Acta Gastroenterol Belg 1999; 62:187-189.

7. Sanna CM, Loriga P, Dessi E, et al. Hyperplastic polyp of the stomach simulating hypertrophic pyloric stenosis. J Pediatr Gastroenterol Nutr 1991;13:204-208.

8. Gencosmanoglu R, Sen-Oran E, Kurtkaya-Yapicier O, Tozun N. Antral hyperplastic polyp causing intermittent gastric outlet obstruction: case report. BMC Gastroenterol 2003;3:16.

9. Jain R, Chetty R. Gastric hyperplastic polyps: a review. Dig Dis Sci 2009;54:1839-1846.

10. Abraham SC. Gastric polyps: Classification and meaning. Pathol Case Rev 2002;7:2-11.

11. Ji F, Wang ZW, Ning JW, Wang QY, Chen JY, Li YM. Effect of drug treatment on hyperplastic gastric polyps infected with Helicobacter pylori: a randomized, controlled trial. World J Gastroenterol 2006;12:1770-1773.

12. Bamba H, Ota S, Arai S, et al. Expression of cyclooxygenase-2 in human hyperplastic gastric polyps. J Exp Clin Cancer Res 2003;22:425-430.

13. Nakajima A, Matsuhashi N, Yazaki Y, Oka T, Sugano K. Details of hyperplastic polyps of the stomach shrinking after anti-Helicobacter pylori therapy. J Gastroenterol 2000;35:372375.

14. Cheon WS, Oh HC, Kim JW, Kim JG. The characteristics of small gastroduodenal polypoid lesion removed by forcep biopsy. Korean J Helicobacter Up Gastrointest Res 2008;8:97-102.

15. Lee SM, Lee KT, Kim SH, et al. Clinicopathologic evaluation of 290 cases involving endoscopic gastric polypectomy. Korean J Gastrointest Endosc 1998;18:832-840.

16. Al-Haddad M, Ward EM, Bouras EP, Raimondo M. Hyperplastic polyps of the gastric antrum in patients with gastrointestinal 
blood loss. Dig Dis Sci 2007;52:105-109.

17. Cherukuri R, Levine MS, Furth EE, Rubesin SE, Laufer I. Giant hyperplastic polyps in the stomach: radiographic findings in seven patients. AJR Am J Roentgenol 2000;175:1445-1448.

18. Heo WS, Chae KH, Jung JH, et al. Two cases of adenocarcinoma arising from gastric hyperplastic polyp. Korean J Gastrointest Endosc 2005;31:399-403.
19. Dang S, McElreath DP, Kumar S, et al. Giant gastric hyperplastic polyp: not always a benign lesion. J Ark Med Soc 2010;107: 89-92.

20. Kang HM, Oh TH, Seo JY, et al. Clinical factors predicting for neoplastic transformation of gastric hyperplastic polyps. Korean J Gastroenterol 2011;58:184-189. 